\title{
Prospective and Retrospective Recurrence Impact on Text Coherence
}

\section{Svetlana Sorokina}

\author{
Senior Lecturer \\ National Research University Higher School of Economics, Moscow \\ lana40ina@mail.ru \\ Olga Musorina
}

Candidate of Science, History;

Penza University of Architecture and Construction

\section{Doi:10.5901/mjss.2013.v4n9p503}

\section{Abstract}

The present research addresses the phenomenon of recurrence at structural, semantic and metatext levels and aims to analyze its impact on the author's argumentative line and text identity. The paper focuses on the use of prospective and retrospective iteration that plays a particularly significant role in scholarly literature where an academic text is due to comply with specific regulations and to report on the research results in the most objective way. To achieve the goal academic writers rely on employing a system of concepts typical of a particular science, providing unquestionable arguments and critical approach to convince the readers and win their trust. Scholarly articles related to management studies have been exposed to content analysis methodology and the findings reveal that recurrence as a multifunctional phenomenon is an integral part of narrative since it structures the composition, discloses the author's intention, supplements well justified reasoning through clarification, interpretation, explanation, accentuation and contributes to text consistency, cohesion and coherence.

Keywords: recurrence, prospective and retrospective exposition, argumentative line, coherence

\section{Introduction}

Since a text is asserted to be a depository and a transmitter of social, cultural, and scientific knowledge the issues related to its lexical and grammar structuring and transporting the results of the writer's thinking process to the readers have a widespread appeal within a scientific context. Scholars pursue varied approaches to the text from purely analytical and structural standpoints (Melchuk, 2001, p. 267) seeing text a hierarchy of words, word combinations, sentences and paragraphs to those highlighting cohesion and coherence as the main text characteristics based on the interpretation of each individual sentence relative to the interpretation of other sentences. (Van Dijk, 1977, 93)

According to Prof. Koshevaya (Koshevaya, 2012, 124) being the most comprehensive speech unit, any text regardless of its genre is perceived a closed completed system, synthesis of perspective and pragmatic aspects, i.e. text content, text semantics, text composition, text structure, semiotics. The definition emphasizing both structural and semantic aspects of text building that occurs at three levels is provided by Prof. Sviridova: 1 . correlative level as a logical and intensional level where the link with the object of thinking is established; 2. corrective level as a language level where all language tools at a certain period are presented; 3 . elective level as a speech level where the synonymous language tools are analyzed and the most appropriate ones are selected by the text author with the purpose to communicate the information with the highest accuracy possible. (Sviridova, 2011, pp.63-66)

Being the nexus of communicative, cognitive and emotive functions, text acts both as a closed system and an open one. Due to its structural limits, completeness and ability to exist independently from either the author or the reader, text turns to be a stationary, closed unit. However, being actualized in the reader's mind during the process of reading and interpreting which alters from reader to reader at different times, text is seen an open, mobile system. (Turaeva, 1986, p.12)

Text is the unity of systemic and individual features since, on the one hand, it has to be built according to conventional models, but, on the other hand, it is created by individuals who inevitably contribute their personality to any, even scholarly texts, which have to meet strict requirements.

The most comprehensive definition of the text is acknowledged to be that by Prof. Galperin who reveals the 
multifaceted nature of the text describing it as the result of a creative speech process fixed in writing in compliance with the principles of a certain genre. Text is argued to be a complete, headlined unit built by the constituents of the language hierarchy with the help of various lexical, grammatical, logical, stylistic links and having intentionality and pragmatic value (Galperin, 1981, p.18).

\subsection{Research goals and methods}

This research addresses a particular type of academic texts - journal articles used by various scholars as one of many sources of evidence about their research subject where language acts not only as a neutral medium for generating subject knowledge, but as a form of social practice and both reflects and constitutes social realities (Silverman, 2000). Some linguists (e.g. Barthes, 1977; Baxter, 2003) go further and assert that the language of research is a textualising practice which requires thorough analysis of its linguistic data and their constitutive power. Thus the paper touches upon scholarly article salient categories and aims to analyse prospective and retrospective recurrence, an integral part of narrative, and its role in structuring the author's argumentative line and providing well justified reasoning. Employing such methods as content analysis, qualitative and quantitative research techniques, the articles devoted to the management aspects and published in "Journal of Management Studies", "Journal of Management", "Strategic Management Journal" have been examined.

\section{Theoretical background}

\subsection{Scholarly Text Categories and Conventions}

It is a well-known fact that scholarly text is to comply with standardized rules and regulations typical of the academic writing. To meet these requirements academic texts employ generally accepted terms, clichés, and lexical and grammar patterns. In addition academic papers intended for publishing have to conform to the conventions of scholarly publishing such as MLA (Modern Language Association) ${ }^{1}$ applied to papers in humanitarian sciences, APA (American Psychological Association) $)^{2}$ typical of papers in medicine, sociology and economics, CMS (Chicago Manual of Style) ${ }^{3}$ used in some social science publications and historical journals, and less spread ones such as AAA (American Anthropological Association) ${ }^{4}$, CSE (Council of Science Editors) ${ }^{5}$ and others.

The standards and conventions of an academic piece of writing have been extensively examined and various aspects of the research article have been analysed: the abstract (Kamler and Thomson, 2004; Lores, 2004; Martin, 2003), introduction (Samraj, 2002, 2005; Swales, 1981), literature review (Kwan, 2006), method (Lim, 2006), results and discussion (Brett, 1994; Holmes, 1997; Hopkins and Dudley-Evans, 1998; Yang and Alison, 2003), acknowledgements (Hyland, 2004), as well as the whole article (Kanoksilapatham, 2005; Nwgou, 1997).

Whatever the variety of scholarly publishing conventions might be, the underlying characteristics of academic style of writing are as follows:

1. at the morphological level the usage of

- abstract nouns (e.g. argumentation, concept, importance)

- verbal nouns (e.g. evaluation, collaboration, exaggeration)

- words of Greek and Latin origin (e.g. academic, heterogeneous, schematic, many words starting with ph-, ps-, sch- - of Greek origin; nexus, insinuation extricate, intricate - of Latin origin)

- passive voice (e.g The data were collected from 105 chief executive officers of Canadian companies. In this paper, a cross-sectional study using a 3-stage organizational life cycle model... is adopted in the examination of the changes in environmental challenges.)

2. at the lexical level the usage of

- terms (e.g. decimal point - in mathematics, balanced scorecard, benchmarking - in management, fusional language, hedged performative - in linguistics)

- clichés or rather extended word collocations accepted in academic writing (e.g. not devoid of some

\footnotetext{
1 The publication manual is available: http://www.mla.org/

${ }^{2}$ The publication manual is available: http://owl.english.purdue.edu/owl/resource/560/01/

${ }_{3}^{3}$ The publication manual is available: http://www.chicagomanualofstyle.org/home.html

${ }^{4}$ The publication manual is available: http://www.aaanet.org/publications/guidelines.cfm

5 The publication manual is available: http://writing.wisc.edu/Handbook/DocCBE.html
} 
serious drawbacks, a deviation from the mainstream, root and branch transformation, it should be stated at the outset)

- $\quad$ academic vocabulary (e.g. hypothesize, subsequent, perspective, portray, invariably)

- iteration within a short context (e.g. A key question in the managerial cognition literature is the extent to which individuals within organizations have similar or different cognitions. The focus of empirical studies, however, has been on cognition related to industry and competition rather than a more comprehensive set of external and internal factors. Cognitive researchers have also been interested in the connection between shared cognitions and behaviours in organizations. )

3. at the syntactical level the predominance of

- complex and compound sentences (e.g. Further greenfield ventures provide an option to expand, increasing the investment incrementally as more information about the market becomes available, allowing firms to create a smaller operation (compared to an acquisition) if demand turns out to be lower than expected, and finally provide a mechanism for abandonment at lower cost than an acquisition (which requires the entire investment be made at the start) if it becomes clear that demand will not materialize.)

- declarative sentences since the key goal of scholarly papers is to report either accumulated or generated knowledge (e.g. The evidence suggests that acquisitions are a good choice only when firms enter markets containing low demand uncertainty and when these firms possess acquisition-based strategic flexibility.)

- $\quad$ noun-based phrases rather than verb-based phrases (e.g. multistage life cycle models; the examination of the changes in environmental, university-based technology commercialization )

In addition to the wide usage of intrinsic lexical, morphological and syntactical patterns scholarly papers seek to conform to the norms and principles underlying the academic writing process such as: conceptuality, empirical approach, criticism, logic, reasonableness. Given these norms, Prof. Galperin suggested the following categories a scholarly text is based on (Galperin 1981:27):

- $\quad$ information value - i.e. texts seek to communicate various data depending on the pragmatic goals

- $\quad$ integration - i.e. every further text segment is semantically linked to the previous one and there is a linear perception of the information even though there may be some deviations from the main narration stream;

- segmentation - i.e. scholarly texts are subdivided into particular segments within their structure depending on the paper type, the invariable segments are introduction, main body and conclusion; research proposals and article also include methodology and result analysis parts, the main requirement is structural clarity;

- modality - i.e. the category aimed at the writer and concerned to reflect the writer's attitude to the potential or actual implication of the data presented in the paper;

- accentuation - i.e. the author emphasizes meaningful issues and attracts the reader's attention with the help of interpreting, clarifying, highlighting with the final aim to convince the reader;

- prospective exposition - i.e. further facts are declared beforehand letting the reader concentrate on reading, mentally prepare for understanding the message and refer to their knowledge background that is crucial for the comprehension of scholarly information;

- retrospective exposition - i.e. the author refers to the previously presented issues essential for further narrative or for reconsideration in new circumstances.

The purpose of these norms and principles is to adequately project the cognitive process structure consisting of setting a problem, defining research tasks, solving the problem, and explaining the results. This is exactly the established structure of almost any research paper that is preconditioned by the author's communicative aim to convince the readers, well informed professionals, that the research is important and the results and valid and reliable. It allows for acknowledging an argumentative nature of the research article.

Since all the premises put forward need to be justified to sound cogent, the arguments are expected to be logically delivered and supplemented with speculation, description, and interpretation to explain and clarify complicated concepts and phenomena and to justify the author's standpoint. Due to a lack of direct contact with the recipient in written communication, the importance of clarity, consistency, cohesion and coherence increases.

\subsection{Research Argumentation}

As it has been mentioned before, the author's key goals while reporting on the research results is to appeal to the readers' thinking, to convince them of the data relevance with the help of adequately structured argumentative line. 
Argumentation is considered a social, intellectual, verbal activity aimed at justifying or refuting a premise and represented by a system of assertions to be understood and shared by a certain audience. (Alekseev, 1991, pp. 30-35) Argumentation in this paper is treated as a communicative process related to the analysis and selection of appropriate arguments based on a premise and well justified reasoning, evaluation of possible alternatives and estimation of their logical consequences.

Being guided by the proposition that argumentation has dual nature: logical in structure and rhetorical in content (Ivin, 2000, p.25), we accept that argumentation is the integrity of two processes: internal related to the selection of the most adequate linguistic forms and external related to the social interaction with the reader aimed at inspiring thinking and convincing.

Moreover, being based on predication, argumentation is considered to be a cognitive process as it generates information perception, processing and representation; a mental process involving speculation, explanation, confirmation, correction, or objection (Gadamer, 1988, p.37); a communicative process aimed at transmitting a message and eliminating cognitive and axiological dissonance interpreted as the deviation between two types or levels of background knowledge. (Festinger, 1985, p.41)

The goal can be achieved if the information presented is profoundly justified, in other words if well-grounded arguments are provided. An argument is claimed to comprise a set of assumptions or premises, a method of reasoning and a conclusion In classical logic the method of reasoning seeks to guarantee the conclusion following logically from the assumptions.

However, in the speculation process there might be a lack of formal structural links between a premise and a conclusion and the analysis of text implies the penetration into the author's intention and the research not only into explicit but also into implicit evidence of argumentation. Text analysis turns to be the process of deriving logical conclusions, i.e. the process of inference based on a set of cognitive operations. This very assumption underlies CARS (Creating a Research Space) model by John Malcolm Swales known for his research into genre analysis. The model comprises recurring and regularized argumentative events - argumentative moves and steps (Swales, 1990):

- establishing a research territory based on the analysis of the previous research and existing theories;

- setting the research subject and importance;

- establishing a research niche based on identifying research gaps;

- occupying the niche based on setting a research problem, defining research tasks and explaining research methods and tools.

A similar model has been put forward by Tony Dudley-Evans, another British linguist and expert in English for Specific Purposes. His Six-Move Schema of Rhetorical Move (Dudley-Evans, 2008) consists of the following steps moves: introduction of the research field, introduction of the general topic, introduction of the particular topic, definition of the particular topic scope, preparation for present research by identifying shortcomings in previous studies, and introduction of present research by setting research goals and methodology.

The both models emphasize the fact that a scholarly text has one central theme and every part contributes to the main point providing speculation on certain phenomena, explanation, and exemplification, i.e. recapitulating, iterating, and recurring to particular standpoints and issues.

\subsection{Recurrence}

The term recurrence comes from Latin "recurre" - repetition, reiteration and can be treated from two perspectives: as an explicit process of repetition at different strata of language and as a universal linguistic phenomenon.

Recurrence may occur at different levels:

- $\quad$ at the structural level of the text where recurrence acts as an explicit phonetic, morphological, lexical and syntactic repetition

- $\quad$ at the semantic level where recurrence exists implicitly as repetition of meanings

- $\quad$ at the metatext level where headings, sentences and even text segments, refrains are repeated

- at the intertextual level where texts include quotations and reference to precedent texts such as legends, proverbs, sayings

It is necessary to mention that recurrence can be investigated only within a text as any language exists in the form of a text, text is believed to be a primary communication element accommodating other language elements that can be induced from the text with the help linguistic analysis. A text of any genre contains recurrent elements of different levels interacting with non-recurrent elements and ensuring text cohesion and coherence. 
Recurrence plays a specific role in scholarly literature where an academic text is due to report on the research results in the most objective way employing a system of concepts typical of a particular science, providing unquestionable arguments and critical approach. Critical approach presupposes speculation, poly-theoretical description, and interpretation variety.

Moreover, text categories also get realized through recurrence since every logical narrative complies with the rule of thumb - say what you are saying (outline the main points of your account), say it (deliver the information) and say what you have said (summarise the main points to make sure all the details have been included). Text writing and reading process is like a spiral evolving movement, the factor of text sense dynamics (Taranets \& Chetyrkina, 2008, p.340-341) where every new reiteration brings new connotations to repeated words, broadens newly expressed ideas, and contributes to argumentation cogency.

Thus, recurrence aims to emphasize the issues which prove to be the most significant for the author's train of thought in terms of building the most logical argumentative line. Moreover, the process of interpreting and comprehending the author's argumentative line is rather challenging especially in case of research article that belongs to a certain area of science, uses certain concepts and requires certain power of apprehension.

As a result of the author's reference to the existing information, recurrence proves to be revealed at two levels:

- intratexual, i.e. within a single text where recurrence seeks to perform the function of segmentation that results in establishing a clear order of presenting the text sections (Strizhenko \& Kruchinina, 1985, p.70)

- intertexual, being or involving the reference of one text by another; here we can speak about citation.

Being a text category, recurrence also occurs as prospective or retrospective exposition, i.e. as the basis for accumulating, retaining, and reassessing information.

Prospective exposition is perceived as a means of text building aimed at providing the opportunity to predict further narration, to comprehend the links between the article parts and issues. Every new section of an article starts with a brief outline of or introduction to the information provided further preparing for critical reading.

Retrospective exposition as a means of text building seeks to:

- $\quad$ restore previously stated points or introduce new ideas related to the previously stated points and necessary for further comprehension of the research report

- let the opportunity to reconsider previously discussed issues in a new context

- actualize some parts of the text which indirectly relate to the intensional information.

Every part of an article finishes by summarizing the key points discussed. Consequently, retrospective recurrence inevitably leads to the reconsideration and reassessment of some issues and standpoints presented in the text making certain, irrelevant at first sight, points meaningful and significant.

Both, prospective and retrospective recurrence may be created by the author with the help of various lexical and semantic patterns, in this case we deal with the actual explicit recurrence, or may be elicited as a result of reader's analysis and critical thinking, in this case the recurrence is implicit, based on the reader's subjective perception.

Thus, prospective and retrospective iteration or recurrence is intentionally used by the author to provide for logical consistency of the article; and can be restored by the reader due to the ability to retain information in mind and draw logical connections between various related issues.

\section{Results and Discussion}

One of the indicators that a certain issue or detail is meaningful to building narration, valuable to revealing the author's intention, and indispensable to the detecting the author's argumentative line is its repeated or recurrent display in the text.

The analysis of CARS model by John Malcolm Swales and Six-Move Schema by Tony Dudley-Evans demonstrates that the former tends to refer only to the introductory part of research paper unlike the latter that addresses the whole paper. However, neither of them straightforwardly mentions such an important move or step in the research report as analysis or discussion of research results. Thus, given the both models we suggest distinguishing the following argumentative, recurrent steps within the framework of a research article

1. Introductory stage:

- Defining the research field

E.g. Conceptually there is substantial agreement that business organizations, both large and small are inseparable from their respective environment. On a continuous basis, changes in the environment bring about new sets or combinations of circumstances that must be dealt with through management 
decisions...

- Defining the research subject

E.g. Thus, the assertion in this research is that organizations respond to their environments on the basis of perceived problems/concerns.

- $\quad$ Setting the research problem

E.g. The purpose of this study is to provide empirical evidence on identified problems/concerns of small business firms dimensioned in terms of changes within the organization. Of particular interest are those related to the organizational life cycle and the exogenous changes attributable to the dynamic, competitive nature of the marketplace.

Thus, the introductory part makes it clear that the research is concerned with such concepts as "business organization", "environment", "problems/concerns", "decision making" creating the basis for the further narration where the stated concepts are expected to be defined and analysed.

2. Theoretical background:

- Key concept definition and explanation

E.g. Problems/concerns may be defined as issues that galvanize interest and direct attention in organizations because of envisioned consequences associated with action or inaction.

- Previous research and existing theory analysis

E.g. ... there are numerous multistage models that use a diverse array of characteristics to explain the phenomenon of organizational development...

... the organizational life cycle has been variously reported to consist of between 3 and 10 stages...

The underlying theory for this classification system is...

- $\quad$ Further research opportunities identification

E.g. While a number of multistage life cycle models have been proposed, none of them offer adequate explanation of why.

It needs to be clarified that in the introduction research concepts are expected to be only introduced, at the theoretical stage they are defined, explained based on the existing theoretical perspectives.

3. New research presentation stage:

- Specifying research goals by putting forward hypotheses, research questions or defining research tasks E.g. Proposition 1: Significant differences in the relative importance of identified problems will exist between organizational task environments.

- Explaining research methods and procedures

E.g. Data for this study were gathered from final case reports ...

A key issue in the analysis began with the simple calculation of ...

The standard $Z$ test was employed to compare...

- Presenting research results

E.g. Specific problem descriptions were categorized under major headings identified in the preliminary stage of data analysis.

... six identified problems exhibit statistically significant differences ...

... significant differences are noted for only two problems in those environments...

At this stage the information is presented on the basis of previously stated and described concepts and standpoints. Such recurrent progressive account of research contributes to cohesion and coherence of scholarly texts where all the issues are introduced in logical connection. In addition at this stage the stipulated research area gets compressed to particular perspectives being examined by corresponding tools.

4. Concluding stage:

- Result analysis

E.g. The findings of this study contradict...

The variable nature of these nine problems allows them to be classified as situational problems.

The findings of the study also provide new insights into how a particular task is interpreted.

- Research significance appraisal

E.g. This research provides a positive perspective of the role that competition and the organizational life cycle play in determining problems...

... this research provides a paradigm by which owners and managers can better allocate resources and...

- Research delimitation appraisal 
E.g. Acknowledging the limitations imposed by the methodological procedures...

Creating journal articles based on this model authors manage to logically recur to the main issues of their account, to draw attention to the most significant premises, and to encourage the reader to speculate on those recurrently highlighted points. This scheme allows for consistent data delivery and provides for article coherence since the issues are recurrently linked both within the whole article and within every stage that is clearly demonstrated by prospective and retrospective recurrence.

Thus, prospective exposition helps to point out the logical plan for a scholarly composition setting the framework for the narration:

"This paper proceeds as follows. First, we develop the self-determination aspect of our model to explain the intensity of the negative emotional reaction to project failure. Second, we develop the self-compassion aspect of our model to explain variance in the relationship between these negative emotions and learning from failure. Finally, we discuss the implications of our model."6

Since the plan for the account is declared, all the issues stated are specified further at greater length:

"We use a self-determination theory perspective to develop a model....."7

"Self-Domination Theory (SDT) is concerned with explicating the psychological processes..."8

"... we investigate how various attributes of self-compassion can ..."9

"...self-compassion involves ..."10

"... with self-compassion the individual seeks to remain connected to organizational actions.11

"We believe that this model has a number of important implications"12

"Although the negative implications of organizational members not thriving at work are already well understood..."13

Intratexual retrospective exposition helps the reader comprehend the consistency of the author's argumentative line.

"However, as stated above, negative emotions can also interfere with learning."14

"Hence, in each local authority questionnaires were sent to two echelons - three corporate officers and seven

officers in each of the seven service areas mentioned above."15

The author recurs to the key issue of the research building the report line according to the classical argument structure presenting an assumption or a premise and moving to the conclusion through testing the proposition and providing the justification for the reasoning. The argumentation process requires the application to the categories of information value, integration and accentuation to ensure cohesion and coherence.

"This simple notion suggests three important insights into the opportunity evaluation decision-making process; specifically: (1) evaluations of opportunity attractiveness - that is, the potential of the opportunity to generate competitive advantage and entrepreneurial returns to the firm - likely proceed and are separate from the decision to exploit; (2) opportunity evaluation is future-focused, such that the entrepreneur evaluates the opportunity in terms of the firm's gains if the opportunity were exploited; and (3) opportunity evaluation represents a first-person - rather than a third-person - assessment" 16

Given the fact that all studies exist within the theoretical environment built by certain concepts and previous research, academic writers tend to refer to other scholars' investigations and findings to demonstrate their belonging to the academic circles, and to contribute to their research reliability. In this case recurrence turns to be intertexual recurrence to previously learnt theories, background knowledge.

\footnotetext{
${ }^{6}$ Shepherd Dean A. and Cardonp Melissa S. (2009), Negative Emotional Reactions to Project Failure and the Self-Compassion to Learn from the Experience, Journal of Management Studies 46:6 September p.925

7 Ibidem: p.927

8 Ibidem:p.927

${ }_{9}$ Shepherd Dean A. and Cardonp Melissa S. (2009), p.931

10 Ibidem: p.933

11 Ibidem: p.933

12 Ibidem: p.938

13 Ibidem: p.938

14 Ibidem: p.930

15 Damanpour Fariborz, Walker Richard, M. and Avellaneda Claudia, N. (2009) Combinative Effects of Innovation Types and Organizational Performance: A Longitudinal Study of Service Organizations, Journal of Management Studies 46:4 June, p.661

${ }^{16}$ Haynie Michael J., Shepherd Dean, A. and McMullen Jeffrey, S.(2009), An Opportunity for Me? The Role of Resources in Opportunity Evaluation Decisions, Journal of Management Studies 46:3 May, p.338
} 
"Smith et al. suggested that companies in the same developmental stage of their organizational life cycle have similar characteristics... In another study, Miller and Friesen conducted an empirical analysis and classified firms..."

Thus, using such text category as recurrence to structure the argumentative line, the author not only ensures logical links within the article but also appeals to the reader's experience that definitely simplifies the understanding of the author's intention alongside with keeping the article compact enough. It is achieved due to the fact that both the author and the reader operate the same concepts and exist within the same theoretical environment.

\section{Conclusions}

The goal of a research paper is not only to inform the reader what others have to say about a topic, but rather to draw upon the existing knowledge in order to thoughtfully offer a unique perspective on the issue at hand, prove the cogency of the suggested vision and deliver the information in the most consistent way possible.

The analysis demonstrates that recurrence as a multifunctional phenomenon is an integral part of academic text since it structures the composition, reveals the author's intention, supplements well justified reasoning through clarification, interpretation, explanation, accentuation and contributes to text consistency, cohesion and coherence.

This paper has placed special emphasis on the prospective and retrospective recurrence and its role in structuring journal articles that proves to be twofold since it exists explicitly, when being created by the author to ensure logical delivery of information, and implicitly, being derived by the reader to get concentrated on the most meaningful issues.

\section{References}

Alekseev, F.P. (1991). Argumentation. Cognition. Communication. Moscow.

Barthes, R. (1977). Image-Music-Text. New York: Hill and Wang.

Baxter, J. (2003). Positioning Gender in Discourse: A Feminist Methodology. Basingstoke: Palgrave.

Brett, P. (1994). A Genre Analysis of the Result Section of Sociology Articles. English for Specific Purposes 13.1: pp.47-60

Dudley-Evans, T. (2008). Developments in English for Specific Purposes Paperback. Cambridge University Press.

Festinger, L. (1985. (first published 1957)). A theory of Cognitive Dissonance. Stanford, CA: Stanford University Press.

Gadamer H. G. (1988). Truth and Method. Moscow.

Galperin, I.R. (1981). Text as an Object of Linguistic Research. Moscow: Science.

Holmes, R. (1997). Genre Analysis, and the Social Sciences: An Investigation of the Structure of Research Article Discussion Sections in Three Disciplines. English for Specific Purposes 16.4: pp.321-338

Hopkins A., and Dudley-Evans T. (1998). A Genre-based Investigation of the Discussion Sections in Articles and Dissertations. English for Specific Purposes 23.3: pp.303-324

Hyland K., (2004). Graduates' Graduate: The Genre Structure of Dissertation Acknowledgements. Methodology in TESOL. Ed. Michael H. Long and Jack C. Richards. Singapore: Harper and Row. Pp.3-9

Ivin, A.A. (2000). Argumentation Theory. Moscow: Gardariky.

Kamler, B., and Thomson P. (2004) Driven to Abstraction: Doctoral Supervision and Writing Pedagogies. Teaching in Higher Education 9.2: pp.195-209.

Kanoksilapatham, B. (2005). Rhetorical Structure of Biochemistry Research Articles. English for Specific Purposes 24.3: pp.269-292.

Kolegaeva, I. (1991). Text as a Unit of Academic and Artistic Communication. Odessa: OGU named after Mechnikov, I.I.

Koshevaya, I.G (2012). Text Building Structures in Language and Speech. Moscow: Book House «LIBROKOM».

Kwan, B. S. C. (2006). Schematic Structure of Literature Reviews in Doctoral Theses of Applied Linguistics. English for Specific Purposes 25.1: pp.30-55.

Lavelle, E.(2003). Quality of University Writing: A Preliminary Analysis of Undergraduate Portfolios. Quality in Higher Education 9.1: pp.87-93.

Lim, J. M. H. (200). Method Sections of Management Research Articles: A Pedagogically Motivated Qualitative Study. English for Specific Purposes 25.3: pp.282-309.

Lores, R. (2004). On RA Abstracts from the Structure to Thematic Organisation. English for Specific Purposes 16.2: pp.119-138.

Martin, P. (2003). A Genre Analysis of English and Spanish Research Paper Abstracts in Experimental Social Sciences. English for Specific Purposes 22.1: pp.25-44

Melchuk, I. N. (2001). Communicative Organization in Natural Language. The Semantic-Communicative Structure of Sentences. Amsterdam/Philadelphia: Benjamins, 2001.

Nwgou, K.N. (1997). The Medical Research Paper: Structure and Functions. English for Specific Purposes 16.2: pp.119-138

Samraj, B. (2002). Introduction in Research Articles: Variation Across Disciplines. English for Specific Purposes 21.1: pp.1-18

Samraj, B. (2005). An Exploration of a Genre Set: Research Articles Abstracts and Introduction in Two Disciplines. English for Specific Purposes 24.2: pp.141- 156 
Silverman, D. (2000). Analysing Talk and Text. In N.K. Denzin and Y.S. Lincoln (eds) Handbook of Qualitative Research (2nd edn). London: Sage.

Strizhenko, A.A. and Kruchinina, L.I. (1985). Peculiarities of Structuring Texts of Different Functional Genres. Irkutsk: Publishing house of Irkutsk University.

Sviridova, L.K.(2004). Role of Emotional Constructions in Realizing the Category of Identity in Dramatic Concept of Plays. Doctoral thesis: 10.02.19 Moscow.

Sviridova, L.K. (2011). Iteration as an Identity Speech Form in Drama. Herald of Moscow State Regional University. «Linguistics».2011. No.6, Vol.2. pp.63-67

Swales, J. (1981). Aspects of Article Introductions. Birmingham: University of Aston Language Studies Unit.

Swales, J. (1990). Genre Analysis: English in Academic and Research Settings. Cambridge: Cambridge UP.

Taranets N.A. (2008). Game Ontology in Post-Modern Discourse. Taranets N.A., Chetyrkina I.A. Philology as the Nexus of Knowledge on the World. Collection of Scientific Papers. Krasnodar. Prosveshcheniye-South .

Turaeva, Z.Y. (1986). Text Linguistics. Text: Structure and Semantics. M: Prosveshcheniye.

Van Dijk, Teun A. (1977). Text an Context. Explorations in the Semantics and Pragmatics of Discource. Longman. London and New York. Longman Publishing House.

Yang, R. and Alison, D. (2003). Research Articles in Applied Linguistics: Moving from Results to Conclusions. English for Specific Purposes 22.4: pp.365-386 